\title{
EDITORIAL
}

\section{Response to Galaznik, Cohen \& Scheimberg, and Rorke-Adams \& Christian}

\author{
Stephen Chapman • Thomas L. Slovis
}

Received: 27 April 2009/Accepted: 27 April 2009/Published online: 30 June 2009

(C) Springer-Verlag 2009

The publication of the paper by Mack et al. [1] has, we believe, generated much discussion, and rightly so. They presented concepts that are new to many of our readers, and one of the ways that medicine advances is when our longheld beliefs are challenged. We have published in this issue a number of letters [2-4] that we have received in response to their paper and the accompanying editorial [5]. In the July issue we published correspondence from Drs. Geddes, Squier, Hobbs and Bilo [6-8] following the publication of the paper by Hobbs and Bilo [9]. It is clear that the paediatric world, whether they be paediatricians, pathologists or radiologists, falls into one of two camps: those who believe that in the absence of a clear medical diagnosis the finding of subdural haemorrhage $( \pm$ other radiological and clinical features) strongly suggests (but is not diagnostic of) inflicted head trauma, and those who believe that non-accidental injury is overdiagnosed and subdural haemorrhage is largely a consequence of severe hypoxia.

There seems to be a belief that one size fits all-that subdural and intradural haemorrhages are intimately related, that macroscopic subdural haemorrhage is the same as microscopic haemorrhage, and that hypoxia provides a unifying initial aetiology. In this context, intradural and

S. Chapman $(\bowtie)$

Radiology Department,

Birmingham Children's Hospital NHS Foundation Trust,

Steelhouse Lane,

Birmingham B4 6NH, UK

e-mail: steve.chapman@bch.nhs.uk

T. L. Slovis

Department of Pediatric Imaging,

Children's Hospital of Michigan,

3901 Beaubien Blvd.,

Detroit, MI 48201, USA subdural haemorrhages seen by the pathologist are largely microscopic features, while the subdural haemorrhages seen by the radiologist are, by definition, macroscopic. In the study of 50 fetuses, neonates and infants described by Geddes et al. [10] only the index case had a subdural haemorrhage visible to the naked eye. It is difficult to believe that the microscopic intradural haemorrhages of the pathologist are the source of the bleeds that we see on CT or MRI. Furthermore, if hypoxia is a potent cause of subdural haemorrhages then why don't we see them more commonly following cardiorespiratory arrest, drowning, etc.? Similarly, non-traumatic causes of brain swelling are not associated with subdural haemorrhage. Why don't we see so-called acute traumatic effusions secondary to known cerebral hypoxia? The subdural haemorrhages seen in newborn infants are common and clearly different from what we see beyond the newborn period [11]; yet even here, trauma must be the predominant cause in the majority. In the series of 25 fetuses and 30 neonates with intradural haemorrhage described by Cohen and Scheimberg [12], the fetuses ranged in gestational age from 26 to 41 weeks, while the oldest neonate died at 19 days of age; the cohort was thus dissimilar to the typical infant with suspected non-accidental injury.

A number of other factors must also be considered when forming our opinion about the causation of unexplained subdural haemorrhages. First, all of us who practice in this arena have our own personal experience of carers who admit to injuring their child, whether that is by shaking, impact or both. These admissions are supported by published data [13]. Second, the child frequently collapses while in the care of a sole carer; it is quite exceptional for such a child to collapse in a public arena or where there are other independent witnesses. Third, many of these children have other traumatic injuries, such as rib fractures or classic metaphyseal lesions: $85 \%$ of cases of subdural haemorrhage/ 
effusion have bruises and/or fractures - important evidence, particularly when death has ensued rapidly, before exhaustive laboratory investigations can be undertaken. While it is true that some children show no other evidence of extracranial trauma, the pattern of neuroimaging findings is identical in those with and without extracranial trauma and in those with and without an admission of guilt.

Clearly we reside within the camp that believes that inflicted head trauma is a real entity. Subdural haemorrhages have many aetiologies and all children should be thoroughly investigated for coagulopathies, metabolic disorders, etc. Maybe our current understanding of the actual pathogenesis of subdural bleeding (tearing of bridging veins) is incorrect, but we should not lose sight of the most important factor in these cases - our duty to protect the child, to be his or her advocate, and to assist the courts using accepted medical wisdom. When the constellation of imaging findings indicates a probable diagnosis of inflicted trauma we have a duty to say so. When the evidence is inconclusive we must not be afraid to say that we don't know; in the UK surveillance data the final diagnosis was undetermined in $9 \%$ of cases [14].

\section{References}

1. Mack J, Squier W, Eastman JT (2009) Anatomy and development of the meninges: implications for subdural collections and CSF circulation. Pediatr Radiol 39:200-210
2. Cohen MC, Scheimberg E (2009) Histology of the dural membrane supports the theoretical considerations of its role in the pathophysiology of subdural collections in nontraumatic circumstances. Pediatr Radiol doi:10.1007/s00247-009-1210-0

3. Galaznik J (2009) Thin-films of subdural hemorrhage in the absence of mechanical trauma: the new challenge of an expanding differential. Pediatr Radiol doi:10.1007/s00247-009-1257-y

4. Rorke-Adams L, Christian C (2009) The emperor has no clothes. Pediatr Radiol doi:10.1007/s00247-009-1290-x

5. Slovis TL, Chapman S (2009) The pathophysiology does not denote the mechanism. Pediatr Radiol 39:197-198

6. Geddes JF (2009) Nonaccidental trauma: clinical aspects and epidemiology of child abuse. Pediatr Radiol 39(7):759

7. Squier W (2009) Nonaccidental trauma: clinical aspects and epidemiology of child abuse. Pediatr Radiol 39(7):758

8. Hobbs JC, Bilo RAC (2009) Response to the letters of Drs. Geddes and Squier. Pediatr Radiol 39(7):760-761

9. Hobbs CJ, Bilo RA (2009) Nonaccidental trauma: clinical aspects and epidemiology of child abuse. Pediatr Radiol 39:457-460

10. Geddes J, Tasker R, Hackshaw A et al (2003) Dural haemorrhage in non traumatic infant deaths: does it explain the bleeding in 'shaken baby syndrome'? Neuropathol Appl Neurobiol 29:14-22

11. Whitby EH, Griffiths PD, Rutter S et al (2004) Frequency and natural history of subdural haemorrhages in babies and relation to obstetric factors. Lancet 363:846-851

12. Cohen MC, Scheimberg I (2008) Evidence of occurrence of intradural and subdural hemorrhage in the perinatal and neonatal period in the context of hypoxic ischemic encephalopathy. An observational study from two referral institutions in the United Kingdom. Pediatr Dev Pathol 63:92-96

13. Starling SP, Patel S, Burke BL et al (2004) Analysis of perpetrator admissions to inflicted traumatic brain injury in children. Arch Pediatr Adolesc Med 158:454-458

14. Hobbs C, Childs A-M, Wynne J et al (2005) Subdural haematoma and effusion in infancy: an epidemiological study. Arch Dis Child 90:952-955 